\title{
Use of active and passive solar systems in residential buildings
}

\author{
S. A. R. Shojaee \\ Department of Architecture and Urbanism, \\ Islamic Azad University of Mashad, Iran
}

\begin{abstract}
The creation of architecture, which successfully applies solar measures, is a complex process. Many factors that go beyond the scope of traditional architectural matters must be taken into consideration. It often happens that the process of creating solar architecture is not integrated into design. There are usually some partial considerations, but the lack of a holistic approach to the project results in unsuccessful solutions. This holistic approach to the solar architecture attempts to differentiate between more and less important problems and looks for optimal solutions. It requires a systematic approach, which defines all the relations (interactions) between environmental factors, use of solar measures and the most important elements of architecture. The main scope of this paper is to analyze these relations. The systematic approach allows for the definition of possibilities/advantages of the solar measures' implementations in the building, as well as shows obstacles and difficulties associated with this process. The paper concentrates on a narrower problem of buildings located in the northern hemisphere in a moderate climatic zone, but some of its conclusions may be valid elsewhere.

Keywords: active and inactive solar systems, architecture, PV module.
\end{abstract}

\section{Introduction}

The constant and increasing environmental degradation, along with the consequent potential hazards, is listed among the most serious and urgent problems humanity has to deal with. The environmental problem, caused by, among other things, large-scale industrial activities, is related to the consumption of conventional energy sources. This consumption, already too large to be 
covered by the existing conventional sources, is constantly growing, since the needs for energy keeps multiplying. What seems to be the answer to this rather crucial challenge is the use of renewable energy sources, such as solar, wind and geothermal energy, in combination with the rationalized use of conventional energy sources, especially in those domains of human activity where large amounts of energy are demanded. One of these domains is the built environment, in a broader sense this includes the building industry, building operation and maintenance etc. The renewable energy source that has been widely used in the building sector is the sun. The use of solar energy has always been a challenge for architects and engineers. The use of sunlight for lighting the interior spaces of a building and for provided heat by solar energy for warming them has been an objective towards the fulfillment of which many techniques have been applied. The selection of window area of a façade taking into account the orientation of this façade, the application of the principles of bioclimatic architecture and the use of passive solar systems are some indicative examples (Kontoleon et al. [15]). During recent decades, the development of photovoltaic technology has led to the possibility of the direct use of solar energy for the production of electricity. A photovoltaic conversion attempts to directly transform all photon energy in light into electricity by taking advantage of the intrinsic photo-effect. Photovoltaic elements can either be building integrated (façade or roof integrated) or not. They can produce large amounts of electricity. Their output depends on various parameters such as temperature, solar radiation on site, effective area $\left(\mathrm{m}^{2}\right)$, shadowing etc. Generally, large-scale, effective use of photovoltaic technology could cover a large part of the world's energy demand.

As a new design concept, ecological building has been emphasized all over the world, and it has become an important subject in the building field. It is the end-result for the ecological building to sufficiently use natural energy such as solar energy, wind energy, and the like, which will lead to the reduction of the dissipation of fossil energy. Solar energy systems therefore have an important role to play. The way solar systems are used is different from what it used to be, however. Buildings are no longer designed to use just passive solar systems or active ones. As a matter of fact, the words passive and active don't make sense any more, as the newer ecological buildings combine several of these technologies. The quest to achieve a safe and comfortable environment has always been one of the main preoccupations of the human race. In ancient times people used experience gained over many years to make the best use of available resources to achieve adequate living conditions. Florides et al. [15] pointed out that as late as the 1960s though, comfortable house conditions were only for the few. From then onwards central air conditioning systems became common in many countries due to the development of mechanical refrigeration and the rise of the standard of living. The oil crisis of the 1970s stimulated intensive research aimed at reducing energy costs. Also, global warming and ozone depletion and the escalating costs of fossil fuels over the last few yeas, have forced governments and engineering bodies to re-examine the whole approach to building design and control. As a result, it is of great importance in the building 
field to reconsider the building structure and exploit the renewable energy systems, which can minimize the energy expenditure and improve thermal comfort. The ecological building concept came into being as an extension of the emphasis on the natural ecosystem balance, and the ecological building concept is the reflection of consanguineous interdependence between the human and the natural environment. As a new design concept, ecological building emphasizes human nature, resource economization, energy conservation and environment protection. By using recycled materials and renewable energy, the sustainable development of living spaces can be achieved. Accordingly, people will live in harmony with the natural environment.

Solar energy is abundant and clean; therefore, it is meaningful to substitute solar energy for conventional energy, which is one of significant characters of ecological building. Solar energy therefore has an important role to play in the building energy system. However, as Hestnes [15] mentioned, the way solar systems are used is different to what it used to be. Buildings are no longer designed to use just passive solar energy systems, such as windows and sunspaces; or active solar systems, such as solar water collectors. In fact, the words passive and active no longer make sense, as the newer buildings combine several of these technologies. They may be energy efficient, solar heated and cooled, and PV powered, i.e. they are simply "solar buildings". Recently, solar water collectors have undergone a rapid development; they are installed with the main purpose of preheating domestic hot water and/or to cover a fraction of the space heating demand. However, this application mainly for obtaining hot water through solar energy is not very consistent with the order of nature. In winter, it is convenient to combine the hot water system with the space heating system just through increasing the collector area. Whereas, for summer with high solar radiant intensity and high ambient air temperature, the demand for air-conditioning and refrigeration is in preference to hot water, this phenomenon is especially obvious in the south. As has been shown from mass media, the prevalence of air-conditioners has brought great pressure upon energy, electricity and the environment. Consequently, solar-powered air-conditioning system would be a perfect scheme because it not only makes the best use of solar energy, but also converts low-grade energy (solar energy) into high-grade energy for comfort. In addition, it is meaningful for energy conservation and environmental protection. Solar cooling has been shown to be technically feasible. It is a particularly attractive application for solar energy, because of the near coincidence of peak cooling loads with the available solar power. The future development trend is building integration of solar energy systems. Hestnes [15] classified solar cooling systems into three categories namely: solar sorption cooling, solar-related systems and solar-mechanical systems. The former two systems are based upon solar thermal utilization and the latter one utilizes a solar-powered prime mover to drive a conventional air-conditioning system. The solar-powered prime mover can either be a Rankine engine or an electric motor based on the solar photovoltaic principle. Kazmerski [15] reported that the photovoltaic panels have a low field efficiency of about $10-15 \%$, depending on the type of cells used, which results in low overall efficiencies for the system. 
Wang [15] showed that, at otherwise identical refrigerating output, the solarmechanical systems are 4 5 times more expensive than those powered by solar thermal utilization. Therefore, the majority of solar-powered air-conditioning systems at present are solar sorption and solar related systems based on solar thermal utilization. According to Grassie and Sheridan [15], in most solar cooling systems, hot water driven single-stage lithium bromide absorption chillers are commonly used. Evacuated tubes or other high-grade solar collectors are adopted to provide a hot water temperature of $88-90^{\circ} \mathrm{C}$ as a heat source to drive the chiller. Experimental data on the performance of such systems were reported by several researchers, such as Bong et al. [15], Li et al. [15], and the like. Although a large potential market exists for this technology, existing solar cooling systems are not competitive with electricity-driven or gas-fired airconditioning systems. The major problems facing solar absorption cooling systems are its high initial cost, low system performance, and solar energy usage for only a short period during each day of operation. Another potential solarpowered air-conditioning system is the solar adsorption cooling system. Adsorption cooling is the other group of sorption air conditioners that utilizes an agent (the adsorbent) to adsorb the moisture from the air (or dry any other gas or liquid) and then uses the evaporative cooling effect to produce cooling. Solar energy can be used to regenerate the drying agent. Solid adsorbents include silica gels, zeolites, synthetic zeolites, activated aluminas, carbons and synthetic polymers. Liquid adsorbents can be water, triethylene glycol solutions of lithium chloride and lithium bromide solutions. Wang [15] suggested that for the mini type solar air-conditioning system, the solar adsorption cooling system may be a better option.

Up to now, the solar-powered adsorption systems have mostly been intermittent and used only for ice making applications. For applications such as air conditioning, when the chilled water temperature requirement is only around 6- $8^{\circ} \mathrm{C}$, two or more adsorption beds can be used to produce a cooling effect continuously. Li et al. [15] established a lumped parameter model to investigate the performance of a solar powered air conditioning system driven by simple flat plate solar collectors. As for working pairs, Dieng et al. [15] described that compared with adsorption systems that require heat sources with temperatures above $100^{\circ} \mathrm{C}$ (zeolite-water systems, activated carbon-methanol systems) and conventional compressor chillers, a silica gel/water adsorption refrigerator uses waste heat at below $100^{\circ} \mathrm{C}$, which would be suitable for a wider range of solar thermal collector types. In this paper, a hybrid system of hot water supply, heating, natural ventilation and air conditioning based on solar energy, which was designed for the ecological building of the Shanghai Institute of Architecture Science, was introduced in detail.

\section{Introducing sun and its radiation energy}

The earth absorbs a small part of the sun's energy that is 5 to 10 times more than the fossil energy that exists on earth. Iran is situated in a highly appropriate location so the use of solar systems can be economical. 


\subsection{Sun radiation}

When sun radiation passes through the earth's atmosphere it divides into two different parts: direct radiation and diffusing radiation. The direct radiation is the part of this radiation that reaches earth without any changes and causes special shadows. The diffusing radiation is the part of the radiation that diffuses when it passes through the atmosphere or it changes its direction. We call both direct and diffusion radiation combined the total radiation. Our common units in evaluating radiation, with attention to its primary parts, are calories on one square centimeter for one minute. For radiation calories we use one square centimeter for an hour or a day or a year, a kilowatt on one square centimeter and for the total radiation, a kilowatt on one square centimeter in one hour.

The radiation of the sun occurs with two different wave lengths. The short wave length consists of 3.3 micrometers. The wave length that is important is 2.5-2.9 and it is called infra red.

\subsection{Solar system}

These systems are the ones used for creating human societies. The different solar systems that exist today are given in the following:

1- Photobiology systems: in this system, solar energy is saved by the photosynthesis of plants and with burning and the fuels such as alcohol or metal is regained.

2- Chemical systems: that are divided into two different groups:

a- Photochemical systems that use the sun's radiation in chemical operations.

b- Hilo metric systems that use the sun as a resource of temperature.

3- Photovoltaic systems: this is a process that converts solar energy to electrical energy without using a movable mechanism. The factor that is used in this system is called solar energy. This system is not economical in many ways because of its high price and vast application which are difficult to overcome. However, much research about solar energy is devoted to this subject.

4- Thermal systems: these systems are the most economical and can be divided into the following groups:

a- cooling and heating systems

b- water heating systems

c- cooling and drying systems

d- pumping systems

e- electricity producing systems

f- green space producing systems

\subsection{Active and passive solar systems}

Active solar systems are the systems that have the equipment to absorb and use solar energy. This equipment can be determined for different conditions automatically but inactive systems or natural systems are used for designing 
buildings in a way, which without using mechanical equipment, they cannot use solar energy for cooling and heating inside the building. Examples are solar walls, the solar room and the thermal diode.

\subsection{The active solar systems}

The active solar systems, dependent on the kind of collectors that are used inside, are of different kinds. These collectors divide into three total groups:

1- Centralized gathering

2- Pipe vacuum gathering

3- Flat gathering.

There are two types of gainer:

1- A gainer with fluid air or gas:

Advantages:

- Highly appropriate for warming the house

- The system and the way it works is very easy

- It doesn't need the change phase for heating (we can send hot air through the place directly)

- It doesn't need maintenance

- It doesn't need fluid prediction, and the subjects such as boiling, freezing and change of its properties

- $\quad$ System leakage doesn't cause damage

Problems:

- They are not appropriate for heating water

- Leakage decreases the output. Finding the source of the leakage is difficult

- A large space is needed for the system (unit of compression with the watery systems)

- It needs electrical energy for changing air (in a watery system, we have to install more pumps inside and the amount of electricity also increases)

2- A gainer with fluid water or other liquids:

Advantages:

- Highly appropriate for apartments and multi unit complexes

- $\quad$ System needs less mass for installing

Problems:

- Its design is highly complex

- If a leakage exists, many financial problems occur.

- The necessity for the existence of precautionary actions in order to prevent building, corrosion and freezing

- System needs maintenance

\section{Parts of system}

\subsection{Collectors}

The solar collectors are simple means that can be built on the building site or in a factory. The base of their work is to use the sun's radiation for heat absorbing 
and transforming it by an inter mediator for the diffusion of heat in buildings. This heat diffusion can be done directly by the collector or by a heat storing unit. The solar collector with the greenhouse effect gathers the heat and uses it for internal consumption of the building. The sun's radiation passes through the glass and a part of it is absorbed by the absorbing surface that then increases its temperature. With an increase in temperature, the absorbing surface starts to create an electric magnetic wave with a high wave length. However, glass is dark for these waves and doesn't let them pass, so heat is trapped behind the glass and its temperature increases. In this part of the paper, we try to explore the total properties of collectors, paying particular attention to the existing equipment, and some proposals for choosing a system are given.

\subsection{Absorbing surface}

The absorbing surface can be made from any kind of material that can absorb or transmit solar radiation. Usually metal, which has high conductive property, is highly suitable for this purpose. For absorbing much greater heat, a black color is used for covering metals such as copper, aluminum brass and galvanized iron, which have the highest heat conductivity. Therefore, these are the most appropriate materials for the absorbing surface.

\subsection{Absorbing plate with air fluid}

In air heating systems, we should pass air from near the absorbing plate.

One of the simplest absorbing plates is metal lance. In this kind of system the air is passed appropriately through the lances and it heats the absorbing plate, which consists of one galvanized plate, which has a thickness of 0.5 millimeters with some trapezoid grooves on it. They are installed on a thin wood plate. Air is heated by passing this absorbing plate and goes out from the possible exits.

\subsection{Absorbing plate with liquid fluid}

The connection of a heat transition pipe with the absorbing plate is very important (in design f-e-h) and so much attention is necessary for installing the pipes to the absorbing plates in this design. Designs (e-f) can be applied with two different connections. One is a parallel pipe connection and the other is series a connection. Since design (d) of has small diameter pipes that have a great loss of pressure, in this design two mental plates are pressed to each other and the fluid movement system is open inside them.

In design (d) two different metal plates are welded to each other. All the designs (g-h) are the simplest given designs that can be applied for industrial and residential use.

\subsection{Covering plates}

Glass is the commonest. It is transparent against the wave length of 2.9-3 micrometers that is important for solar energy. Some kinds of plastics are also 
used as a covering plate but we should note that they don't have the same property from the point of view of the greenhouse effect. Two kinds of plastic named Teflon and lemon have properties like glass - lemon having a high resistance against breakage. Although it is more expensive than glass, the use of plastic is highly effective in places that the solar gainers are near to breaking or are damaged.

\section{Angles and the orientation of installation for collectors}

The effectiveness of these collectors depends a great deal on the time of the year so that the system can be used for collecting the maximum amount of solar energy. In summer the steeple of the collector should be 10 or 15 degree less and in winter it should be 10 or 15 degrees more than the latitude of the location.

The most appropriate solar azimuth angle is zero degrees, in front of south for the northern hemisphere. However, research shows that the diversion degree doesn't have a great effect when using solar collectors. It is necessary for the plate of the collectors to be changed according to the climate and its orientation.

\section{Different kinds of flat collectors}

- Parallel connection - direct return.

- Parallel connection - inverse return.

- The series connection.

\subsection{Thermal fluid transportation}

The necessity for using solar energy is that there is a means for transmitting and distributing energy from the collectors to the saver unit. This action is usually carried out by the gases or liquids as a result of the obligation currency that is caused by the sail in the gas system and pumps in liquid systems. The amount of fluid flow in pipes or channels of the collector should be as much as the gained heat for transmitting. On the other hand, heat, which is absorbed in the plate, increases and reaches the point that the amount of heat loss for the environment is equal to the absorbing heat. The best situation occurs when the atmosphere of this plate is at the minimum amount, which is possible.

\section{Conclusions}

As the result of interactions between solar measures and architectural features some difficulties may appear. These obstacles are caused by a confrontation of solar energetic aspects and purely architectural matters. All five features of architecture must be taken into consideration, since all of them exert an influence. Considering all of these features, one can identify some typical obstacles. 


\subsection{Urbanism}

Site context is disadvantageous for the free choice of solar element location, orientation and reduction of the total helio active surface area, on the other hand: it may be not possible to rearrange site context (e.g. in city centers).

\subsection{Function}

Functional arrangements without satisfactory large areas of construction (e.g. open plan offices with a large area of glazed external walls) are disadvantageous, on the other hand it may be highly desirable for functional, environmental and aesthetical reasons to retain the open plan area.

\subsection{Utility features}

Areas of high quality thermal and visual inner conditions can cause:

- Limitations for external solar element usage (e.g. opaque/semitransparent PV modules within a glazed elevation),

- $\quad$ The need for the creation of buffer zones

On the other hand, the external solar elements may be valuable in the view of the aesthetics of the building and the creation of buffer zones may be not reasonable in confrontation with the assumed functional program of the building.

\subsection{Structure}

- An exposed structural system is not beneficial for the free choice of the location of solar elements within the elevation.

- Poorly insulated structural materials (e.g. steel frames as a support for glasshouses) lead to the reduction of the efficiency of passive solar measures.

On the other hand, exposed structural systems may be useful for other solar elements (e.g. the shadowing system), poorly insulated materials like steel are characterized by thin profiles which are advantageous for the efficiency of solar energy usage (enabling solar rays to be let in).

\subsection{Aesthetics}

The aesthetics of the façade as a factor imposing solutions is not beneficial in view of energy savings, e.g.:

- Technological solutions (e.g. the need to introduce semitransparent modules with relatively fewer PV cells).

- Flat plate solar collectors mounted on the vertical surface as an interesting aesthetical tool but prone to being shaded and inefficient due to their inclination of 90 degrees.

- Limitation of the total helioactive area (e.g. the need to introduce windows as a scaling element among the PV modules system). On the other hand, solar elements settled within the roof (which is most 
advantageous in the realm of solar energy usage) may be poorly visible from the ground level. Their aesthetical role will decrease.

The solar architecture system is a valuable tool if it manages to reconcile energy saving and architectural requirements. The point is to find priorities which are different in every case and which depend on the environmental context, solar concept and all five features of architecture. The confrontation of all these elements involved in the creation of the solar energy system may contribute to finding optimal solar solutions or the next generation of these buildings.

\section{References}

[1] Crisper Jone, Kreit Frank, Solar heating and cooling hemisphere, Publishing Group, 2001

[2] Solar dwelling design concept, by the AIA research corporation, Washington DC, 1998

[3] Solar heating and cooling demonstration program, US Department of Housing and Urban Development, July, 2002

[4] Kaldikot, Helen, If you like this planet, Mansoor Asemi, Paz Publication, 2001

[5] Halasi, Daniel, The start of solar era hosein jalali, the Institute of Book Translation, 2000

[6] Wat, Kenet, The naturalism basics, abdol hosein vahabzade, Mashhad University Center, 2001

[7] Yolan, Iyoo, The third world and the natural crisis, nanoochehr firooz asgari, Ferdosi University of Mashhad, 2001

[8] Tanz, Michale, The energy crisis, mahmood riazi, Sepehr Publication, Tehran, 2000

[9] Ezatolah Azad, Hosein panahandemjalal ghem maghami, faramarz geola, solar energy, the first and second one, Tehran University, 2004

[10] Raoofi Rad, Majid, describing the solar energy systems, Telvin Publication, 1995

[11] Roshan, Amanolah, The usage of solar energy in house, factory and farm, 1996

[12] Wider, Sel, A preface of using solar energy for engineers, ahmad navabi, Astane Ghods Publication, 1996

[13] Texts from sofe, a scientific magazine for architecture and urbanism, 19962001

[14] A research: the design of building with saving the thermal energy. Elm va sanat University, 1988

[15] Report of Ministry of Energy Japan, sustainable world conference, Tokyo 2005 